\title{
Correction to: Mathematical Modelling Education in East and West
}

\author{
Frederick Koon Shing Leung (D, Gloria Ann Stillman (D, Gabriele Kaiser ${ }^{D}$, \\ and Ka Lok Wong
}

\section{Correction to:}

F. K. S. Leung et al. (eds.),

Mathematical Modelling Education in East and West, International Perspectives on the Teaching and Learning of Mathematical Modelling, https://doi.org/10.1007/978-3-030-66996-6

The book was inadvertently published with an incorrect first name and last name for the chapter author have been corrected in the chapter 2 .

And

The volume editor has missed include one of the approved chapter 55 in this book, chapter 55 have been inserted.

The correction chapters and the book have been updated with changes. 